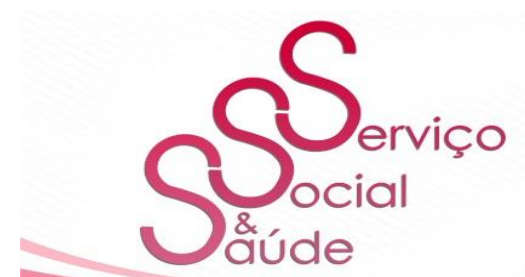

ISSN 2446-5992

(c) (i) (-)

doi: $10.20396 /$ sss.v18i0.8658677

\title{
O agir avaliativo entre seus dois polos ${ }^{1}$
}

The evaluative action between two poles

l'agir évaluatif entre ses deux pôles

Yves Schwartz ${ }^{2}$

\section{RESUMO}

Toda avaliação de assuntos humanos deve aceitar que dois tipos de valores estão envolvidos e, portanto, requerem duas abordagens diferentes para a avaliação. A primeira, cuja missão é avaliar o grau de respeito do "valor do saber": esses saberes criados na desaderência em relação ao espaço e ao do tempo do agir singular de cada ser humano, cujos conceitos científicos são o paradigma, mas que também incluem saberes técnicos, as normas jurídicas, sociais, organizacionais. E a segunda, que deve avaliar os saberes vinculados a esse agir singular que, diante da renovada variabilidade das situações de vida, tentam produzir uma existência, se possível fecunda e provedora de saúde, o que podemos chamar de saberes-valores. Portanto, não pode haver um princípio único de avaliação, e o problema é procurar construir sinergias que respeitem e articulem, dinamicamente, esses dois tipos de relação entre saber e valor.

PALAVRA-CHAVE: Educação. Atividade de trabalho. Norma. Avaliação Educacional

\footnotetext{
${ }^{1}$ Conferência proferida no $31^{\circ}$ Colóquio do ADMEE-Europe sob o título "Entre normalização, controle e desenvolvimento formativo: avaliação fontes de sinergias?" (Entre normalisation, contrôle et développement formatif : évaluations sources de synergies?). Colóquio realizado em Lausanne, Suíça, entre os dias 8 e 10 de janeiro de 2019. Tradução de Isaque Toledo Zimmermann, Revisão técnica de Edna Maria Goulart Joazeiro, com aprovação do autor. Publicada em língua francesa pela Revue Education Permanente, 2019.3, n $^{\circ} 220-221$, p. 315-328.

${ }^{2}$ Filósofo, Professor Emérito da Aix-Marseille Université, Aix-en-Provence. Presidente da Sociedade Internacional de Ergologia, Paris, França. Membro Correspondente da Academie des Sciences Morales et Politiques do Institut de France. E-mail: yves.schwartz@univ-amu.fr.
} 


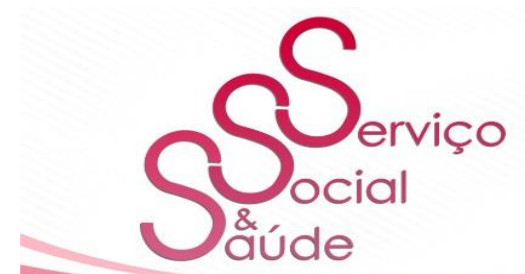

ISSN 2446-5992

(c) (i)

doi: $10.20396 /$ sss.v18i0.8658677

\section{ABSTRACT}

Every assessment of human affairs must accept that two types of values are involved and therefore require two different approaches to assessment. The first, its mission is to assess the degree of respect for the "value of knowing": this knowing created in disregard for the space and time of the singular act of each human being whose scientific concepts are the paradigm, but which also include technical knowhow, legal, social, organizational norms. And the second, which must evaluate the knowledge linked to this singular act that in view of the renewed variability of life situations try to produce an existence. If possible fruitful and health provider, what we can call knowing-values. Therefore, there cannot be a single principle of evaluation and the problem is to build synergies that dynamically respect and articulate these two types of relationships between knowledge and value

KEYWORDS: Educacion. Work activity. Norm. Educational evaluation

\section{RESUMÉ}

Toute évaluation des affaires humaines doit accepter que deux types de valeurs y sont en jeu, et donc deux démarches différentes d'évaluation. Celle qui a pour mission d'évaluer le degré de respect de la " valeur du savoir» : ces savoirs créés dans la desadhérence par rapport à l'espace et au au temps des agirs singuliers, dont les concepts scientifiques sont le paradigme, mais dont relèvent aussi les savoirs techniques, les normes juridiques, sociales, organisationnelles. Et celle qui doit évaluer les savoirs noués à ces agirs singuliers qui, affrontés à la variabilité renouvelée des situations de vie, essaient de produire une existence si possible féconde et pourvoyeuse de santé, ce qu'on peut appeler des savoirsvaleurs. Il ne peut y avoir donc de principe unique d'évaluation, et le problème est de chercher à construire des synergies respectant et articulant dynamiquement ces deux types de rapports entre savoirs et valeur.

MOTS-CLÉS: Éducation. Activité de travail. Norme. Évaluation de l'éducation

\section{INTRODUÇÃO}

O paradoxo da avaliação: uma prática tanto necessária quanto, eminentemente, problemática.

Necessário: de onde vem que parece necessário avaliar o agir humano em todos os tipos de circunstâncias sociais? Se o agir fosse determinado pelos princípios ou protocolos que o antecipam e o estruturam - técnicas, regras, prescrições - não haveria nada a avaliar, nenhuma distância entre a "promessa" de resultados e esses resultados. Entre a entrada e a saída de uma máquina, é necessário avaliar o trabalho realmente realizado, devido às perdas por diversos

\begin{tabular}{|l|l|l|l|l|l|l|}
\hline Serv. Soc. \& Saúde & Campinas, SP & v. 18 & $1-22$ & e019013 & 2019 & e-ISSN 2446-5992
\end{tabular}




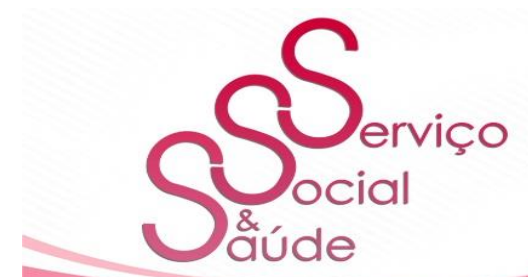

ISSN 2446-5992

(c) (1) (-)

doi: 10.20396/sss.v18i0.8658677

atritos, pela entropia produzida, que se pode bem prever e calcular. Mas entre a entrada antecipada e o produto na saída, não há uma enigmática metabolização, própria ao contrário ao agir humano: esse agir humano em um espaço, visível ou invisível, entre o programa e os resultados, avalia: avalia o que se espera dele, relacionado a uma situação da qual ele avalia também as possibilidades e as coerções. Ao fazê-lo, se avalia a si mesmo. Por isso, mesmo no infinitesimal, (re)usina esses princípios que antecipam seu agir, incluindo a legitimidade que os enunciam. Os "atritos" não são da mesma natureza que para a máquina, então haverá sempre uma distância. Essa usinagem é, portanto, largamente não antecipável.

Um paradoxo, então: porque sempre haverá uma distância, cabe à sabedoria mesmo procurar apreciá-la. A avaliação é, portanto, absolutamente necessária em todos os aspectos da vida social, para conduzir uma política, para não (se)governar às cegas. Mas o que torna a avaliação uma das atividades humanas necessárias (a metabolização não é um "atrito") é justamente o que limita as suas ambições: quais conclusões podem ser tiradas se essa metabolização permanece sempre largamente não antecipável?

No entanto, se admitimos que toda governança das atividades humanas não pode deixar de se mover na incerteza e no desconforto, o que é problemático não deve contrariar o que é necessário, mas, nessas várias circunstâncias a refletir, incessantemente o problemático deve (re)interrogar o necessário: então, a desconfortável avaliação, com seus riscos, pode buscar promover "sinergias" entre esses dois polos, aquele do necessário e aquele que torna o primeiro desconfortável. Isto pela mediação de um terceiro termo, o de um "mundo comum a construir".

\section{O "turbilhão" da avaliação}

Após essas considerações introdutórias bastante abstratas, remetemos ao problema dentro da história. Breve lembrete: como em todos os tipos de circunstâncias somos convidados, ou mesmo convocados, para essas práticas avaliativas? Lembremo-nos que Jean-Marie de Ketele (2010) distingue três diferentes objetivos ou práticas de avaliação: a certificação (a mais comum, mas não a mais profissional), a avaliação para melhorar uma ação em curso, (regulação

\begin{tabular}{|l|l|l|l|l|l|l|}
\hline Serv. Soc. \& Saúde & Campinas, SP & v. 18 & $1-22$ & e019013 & 2019 & e-ISSN 2446-5992
\end{tabular}




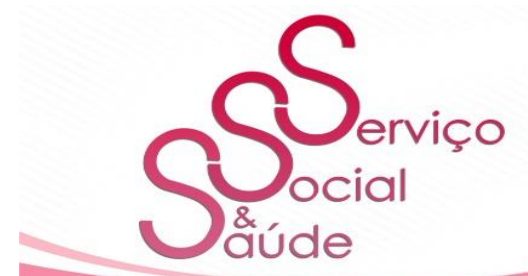

ISSN 2446-5992

(c) (1) (-)

doi: $10.20396 /$ sss.v18i0.8658677

ou avaliação formativa) e a avaliação para orientar uma nova ação a empreender, a avaliação de orientação.

Em quais campos, o agir avaliativo é convocado? Maciçamente, claro, no campo da educação, da formação, da pesquisa, como evidenciado pela ADMEE. Muitos debates se interrogam sobre quais, dentre esses três objetivos evocados, são visados.

Certo, que a questão não é nova: ver a longa história dos testes (para padronizar ou contextualizar?). O que avaliam os testes PISA? Meus colegas aqui sabem muito mais do que eu sobre essas questões. Mas na França, na atualidade se insiste: nosso Ministro quer desenvolver uma "cultura de avaliação", ele cria um Conselho de Avaliação da Escola (CEE), que deve substituir, - se eu bem compreendi - o Conselho Nacional de Avaliação do Sistema Escolar (CNESCO, sigla em francês), isso leva a protestos e debates sobre os princípios e objetivos da referida avaliação. Estamos "nos afogando nas avaliações". Trata-se de avaliar o que? Os alunos? Nesse caso, trata-se de certificar os resultados obtidos, a partir de objetivos padronizados, ou de avaliar os métodos para obtê-los, com apelo, muito debatido nos meios das Ciências da Educação, nas Ciências Cognitivas? Ou avaliar os professores, a partir desses resultados? Ou avaliar os estabelecimentos, que podem estar em situação de concorrência?

O Ensino Superior não foi deixado para trás. Mencionemos o ranking de Xangai: o que ele avalia? O Alto Conselho de Avaliação da Pesquisa e do Ensino Superior (HCÉRES, sigla em francês para Haut Conseil de l'Évaluation de la Recherche et de l'Enseignement Supérieur). A questão dos objetivos, dos métodos, das personalidades do HCÈRES se coloca com maior virulência porque, nesse caso, os pares avaliam os pares: com que critérios? Quem é legítimo para decidir quais são os conteúdos e os métodos de pesquisa pertinentes? Os cientistas são os únicos juízes de programas de pesquisa a serem financiados com dinheiro público? A questão surge com a mesma tensão para as avaliações das publicações de pesquisa. E também para a avaliação de carreiras, e dos dossiês de candidatura. No Canadá, na Universidade Ryerson acabou de ser confirmado que as avaliações de ensino dos alunos não são um barômetro para

\begin{tabular}{|l|l|l|l|l|l|l|}
\hline Serv. Soc. \& Saúde & Campinas, SP & v. 18 & $1-22$ & e019013 & 2019 & e-ISSN 2446-5992
\end{tabular}




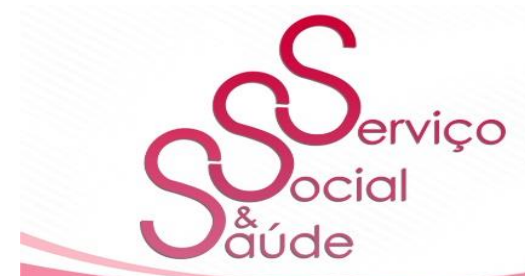

ISSN 2446-5992

(c) (1) (-)

doi: 10.20396/sss.v18i0.8658677

medir a eficácia do ensino de um professor ( $\mathrm{O}$ fim dos questionários de avaliação de alunos ${ }^{3}$ ? (2018)

$\mathrm{Na}$ articulação da vida profissional e da formação, a prática da "validação de aquisições profissionais" (VAP) e a validação de aquisições da experiência (VAE), em minha opinião, colocam problemas de fundo, pois nos leva ao encontro diretamente com o enigma da atividade humana, essa "metabolização", que está no cerne do nosso problema. Veja o trabalho estimulante e os textos de Patrick Rywalski ${ }^{4}$ do Institut Fédéral des Hautes Études en Formation Professionnelle, o (IFFP, sigla em francês do Instituto Federal de Altos Estudos em Formação Profissional) em Lausanne. As mesmas observações para todas as formas de avaliação e de balanço das competências.

Mas o escolar e a formação não são a única questão, longe disso. No campo da economia, da gestão: o que é avaliado para criar estratégias (contratação, demissão, realocação, reorganização ...)? Quais filosofias estão em ação nos indicadores, nas ratios (nos índices) que servem para decidir? O que avaliam as empresas de auditoria, as agências de classificação das políticas econômicas: o que é levado em consideração e em nome de quê?

A política não é deixada de fora, "A avaliação, a nova moda dos deputados LRM" (2018). Como saber se o dinheiro público não é desperdiçado? Como saber se as leis estão sendo implementadas e se apresentam o efeito desejado? Dois casos franceses ilustram essa tão problemática e, portanto, tão necessária procura de uma medida política, o crédito do imposto para a competitividade e o emprego e o efeito da ISF (Imposto de Solidariedade sobre a Fortuna): como identificar os efeitos mensuráveis? E, enquanto isso se cria um eixo "avaliação da democracia" no Laboratório Interdisciplinar de Avaliação de Políticas Públicas (LIEPP, sigla em francês de Laboratoire d'Évaluation Interdisciplinaire des Politiques Publiques). Mas como se define a democracia, o que a gente se propôs avaliar?

\footnotetext{
${ }^{3}$ Cf. « La fin des questionnaires d'évaluation par les étudiants ? » (ACPPU, 2018).

${ }^{4}$ Rywalski (2004; 2012), Cortessis, Salini e Rywalski (2013).
}

\begin{tabular}{|l|l|l|l|l|l|l|}
\hline Serv. Soc. \& Saúde & Campinas, SP & v. 18 & $1-22$ & e019013 & 2019 & e-ISSN 2446-5992
\end{tabular}




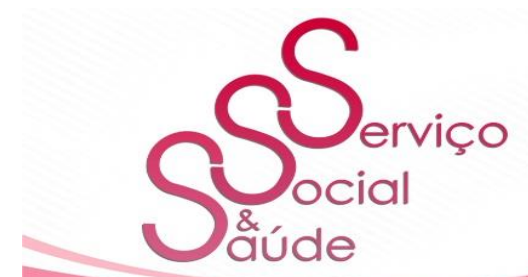

ISSN 2446-5992

(c) (1) (-)

doi: $10.20396 /$ sss.v18i0.8658677

Em suma, nós estamos num turbilhão diante dessa multiplicação de circunstâncias de avaliação: não tanto pelo projeto em si, sempre legítimo, mas pela fragilidade de objetivos, métodos, critérios e, finalmente, de protagonistas, muitas vezes autolegitimados da avaliação.

\section{Dupla polaridade, uma tese antropológica}

Voltemos ao paradoxo inicial do necessário e do que o torna desconfortável. Refere-se ao próprio título do nosso Simpósio: entre a normalização e o controle de um lado (o necessário) e o desenvolvimento formativo de outro (que desloca e enfraquece o ponto de vista do antecedente). Diz-se que este primeiro polo é necessário, mas o segundo, aquele da metabolização, limita radicalmente as suas ambições.

Nossa única ambição aqui seria a de situar esse paradoxo no seio de uma certa antropologia filosófica que denominamos de ergologia por vinte anos, como uma abordagem para a atividade humana. Lendo o tema do Simpósio ADMEE, fiquei impressionado com o fato de que ele expressa no campo da educação essa implicação antropológica, que eu encontro nas três abordagens para a avaliação mencionada na conferência inaugural por Gerard Figari. Essa antropologia faz parecer que não se pode escapar dessa polarização, desse "turbilhão"; mas ela mostra, ao mesmo tempo, que a própria vida deve negociar constantemente, mais ou menos bem, sinergias entre os dois polos; e que ela estará sempre a procura do terceiro para construir essas sinergias...

\section{A avaliação é, portanto, feita ou deve navegar entre dois polos}

Vamos chamar o primeiro polo o da desaderência. Próprio da espécie humana ele reenvia à capacidade de produzir e manipular representações em absentia, esquemas de pensamento que, em graus variados, neutralizam o fato de que a vida nos imerge em um aqui e agora (hic e nunc) que nunca é a reprodução fiel do geral. Nesse primeiro polo, se produz a desaderência do real cercado de singularidades. Essa prodigiosa e fecunda capacidade de se 


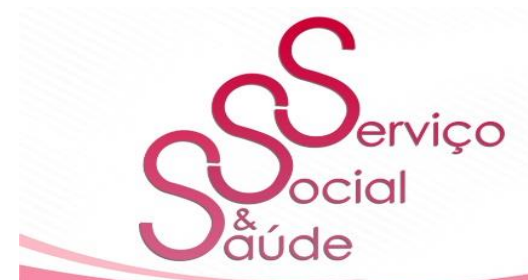

ISSN 2446-5992

(c) (i) (-)

doi: $10.20396 /$ sss.v18i0.8658677

desconectar vai bifurcar-se em dois feixes.

Primeiro feixe: como o antropólogo Maurice Godelier (1984) afirma tão bem, "contrariamente aos outros animais sociais, os homens não se contentam de viver em sociedade; eles produzem a sociedade para viver" (p. 9). Eles devem produzir a sociedade, logo, o conteúdo do viver (como se alimentar, se vestir, se reproduzir...?) não depende diretamente de um patrimônio genético, mas é, no limite, inventado, socializado, e, como tal, valorizado de população a população, uma diferente da outra. Sem normas, - que, segundo diferentes graus de coerções, preveem como organizar a vida coletiva e, notadamente, o que e como caçar, colher, quais métodos para fabricar as ferramentas de sobrevivência, - nenhuma vida humana é possível. A exigência do que chamamos de "normas antecedentes", situadas no polo da desaderência, não cessa de se desdobrar na história humana, com a multiplicidade, a heterogeneidade, os diversos níveis de coerções dessas normas.

O segundo feixe reenvia a emergência da linguagem articulada, que pode evocar in absentia objetos, situações; em uma preocupação contínua com a generalidade e a desaderência, a linguagem produz conceitos, até seu polo extremo do conceito científico. Ponto assintomático da neutralização do aqui-agora (hic e nunc), o conceito científico ambiciona ser instrumento de enunciação de leis e modelos, independentemente do momento e do local de sua enunciação. Isto é o que bem expressam os físico-químicos quando, sob a reserva de condições normais de temperatura e pressão ambiente, ou seja, num ambiente "fora do tempo e do espaço", ou, pelo menos, um tempo e espaço particularizados, os enunciados têm a ambição de ser universalmente válidas ${ }^{5}$.

Compreende-se bem como esses dois diferentes níveis de desconexão vão progressivamente, se apoiar um sobre o outro, para tornar, mais forte o polo da desaderência: as normas da vida coletiva usarão a linguagem, os conceitos, para organizar, regular, prescrever as leis, as maneiras de fazer e de agir, nos registros cada vez mais amplos, para estabilizar de

\footnotetext{
${ }^{5}$ Cf. Schwartz e Durrive (2009, p. 61 et seq.)
} 


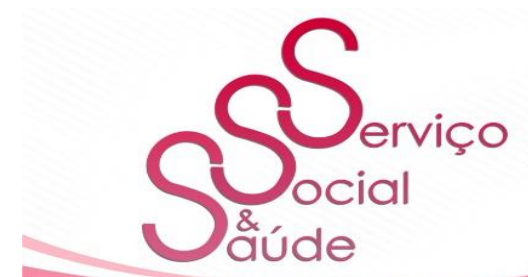

ISSN 2446-5992

(c) $(1)(9)$

doi: 10.20396/sss.v18i0.8658677

forma mais ou menos coercitiva a vida em comum. Ao mesmo tempo, através dessa ascese da desaderência, os conceitos tornam possível a Astronomia, as Matemáticas, a Filosofia, o Direito ... E, a ciência moderna se esforçará para "racionalizar" o imemorial fazer técnico, já que nossas ambições de vida só fazem sentido em um mundo atravessado pela conceitualidade técnica, a aprendizagem de diversos níveis desses conceitos se tornará uma condição de possibilidade da vida em sociedade.

Isso para dizer que o polo da desaderência, que, portanto, inclui os exercícios de controle, de certificação, de normalização, como avaliações do grau de apropriação dessas normas antecedentes, desses conceitos onipresentes em todo projeto da vida social, esse polo é constitutivo de nossa humanidade. Essa avaliação reenvia aos níveis de aprendizagem dessas normas consideradas como depositárias implícita ou explícitamente, com ou sem razão, a axiologia de viver juntos. Essas práticas de controle aparecem em todas as suas necessidades para quem quer socializar crianças provindas de homes e mulheres.

Mas esse polo reenvia apenas a uma parte do nosso ser antropológico. Depois de anos de frequência nos meios de trabalho e de trocas, no contexto da formação universitária dedicada ao conhecimento do trabalho, com os interlocutores profissionais provenientes de todos os horizontes, percebemos a evidência: viver é estar, se não em constante controvérsia, ao menos, em debate com esse polo de desaderência.

No polo oposto, naquele da aderência, nós acreditamos poder afirmar que toda atividade (de trabalho) é sempre no aqui e agora uso de si, sendo no mesmo ato, enigmaticamente, uso de si pelos outros e uso de si por si mesmo. Foi isso que os estudos ergonômicos nos ensinaram sobre as situações de trabalho (aquelas supostamente reguladas por uma organização "científica" do trabalho), onde, no entanto, essas normas antecedentes não pareciam deixar o menor espaço para um retrabalho ou um reajustamento criativo dessas normas, retrabalho que chamamos de "renormalizações". Ao raciocinar a fortiori, estendemos essa afirmação a todas as formas de atividade humana. Ao afirmar esse postulado - que não podemos justificar aqui - que é para um ser humano, impossível e não vivível ser um ser estrito

\begin{tabular}{|l|l|l|l|l|l|l|}
\hline Serv. Soc. \& Saúde & Campinas, SP & v. 18 & $1-22$ & e019013 & 2019 & e-ISSN 2446-5992
\end{tabular}




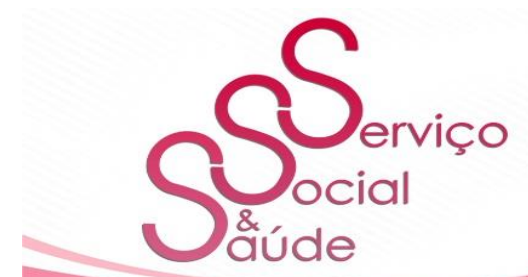

ISSN 2446-5992

(c) 10 (2)(2)

doi: 10.20396/sss.v18i0.8658677

executor de normas antecedentes. Como sintetizou tão bem Georges Canguilhem (2012) na apresentação em 1988 de nossa tese, "Fazer a qualquer distância aquilo que é prescrito fazer, quer dizer, literalmente, fazer uso de si mesmo, tomar-se como um sujeito microparticipante inescapável de operações produtivas" (SCHWARTZ, p. 21). Com o uso de si mesmo, passamos dos atritos mecânicos à metabolização humana. E é aí que a questão da avaliação ficará mais difícil.

Na verdade, toda renormalização de uma sequência operatória prescrita em uma linha de montagem ou em um método de classificação do dever escolar, seguindo essa metabolização que é o uso de si mesmo, essas renormalizações fazem história. Isso significa dizer que, mesmo no infinitesimal, o conteúdo do modelizar, do antecipar em desaderência, na exterioridade das sequências da atividade humana, será sempre parcialmente surpreendido, sempre repensado porque algo novo será criado: bom ou mau, é uma outra história. No polo da aderência, o uso de si mesmo enfraquece, inevitavelmente, a potência do prescrito e do antecipado em situações de desaderência, que é também aquela do controle, da normalização.

Sobretudo, se há um debate de normas - é humanamente impossível e não vivível que esse não ocorra - para agir, para viver, deve-se decidir (trata-se da renormalização). Portanto, devemos preferir: auxiliar o vizinho ou não desviar o olhar da tela do computador, informar melhor um cliente ou preservar o tempo prescrito para cada usuário? Isso significa que cada microgesto, cada reajustamento, cada renormalização das normas antecedentes é uma escolha, logo, uma escolha de valor em nós mesmos, que a torna possível. E esses valores? Qual é o grau de presença em nossa consciência? Como esse mundo de valores se retrabalha no calor da experiência? Enormes problemas que não podemos desenvolver aqui. Mas o fato nos parece incontestável: as sequências da atividade humana são uma sucessão, mas também um emaranhado no seio de um si que será melhor chamado de um corpo-si, de julgamentos, de avaliações, de debates de normas das quais são derivadas, na maioria das vezes, no instantâneo e no inaparente, as renormalizações. A avaliação no polo de desaderência e do controle não deve, portanto, esquecer esse ensinamento específico da ergologia: toda ação humana será

\begin{tabular}{|l|l|l|l|l|l|l|}
\hline Serv. Soc. \& Saúde & Campinas, SP & v. 18 & $1-22$ & e019013 & 2019 & e-ISSN 2446-5992
\end{tabular}




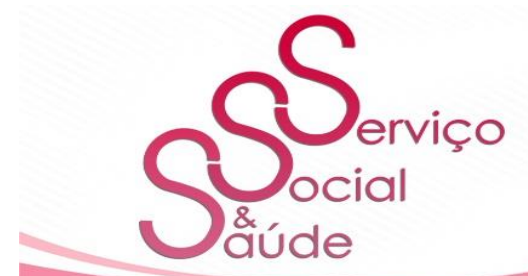

ISSN 2446-5992

(c) 10 (2)(2)

doi: 10.20396/sss.v18i0.8658677

sempre um debate, mesmo um conflito de avaliação, entre normas e saberes valorizados no polo da desaderência e saberes e valores ligados ao corpo-si em ação.

As avaliações reenviam, portanto, a dois mundos de valores, duas diferentes fontes de valorização. Aqueles que se fundam nas normas antecedentes a montante, relativamente estabilizadas no polo da desaderência, como os procedimentos de trabalho, as normas de polidez, o nível exigido no cálculo no final do ensino primário ... independentemente de todo o ponto de vista singular. A outra, pelo contrário, reenvia à história de corpos-si singulares, em debate com os precedentes. A seu modo, eles também visam um mundo comum a viver, todo obscuro e fluído como a dimensão axiológica que o banha. É verdade num minúsculo exemplo: por trás de prestar atenção às dificuldades do vizinho ou de se concentrar em sua tela, existem verdadeiras linhas de opções na vida social. Acrescentemos que não há forçosamente uma distância e, felizmente, entre essas duas fontes de valores: posso, sem mesmo pensar, atravessar as passagens de pedestres, porque adiro aos valores que fundam as normas civis de segurança.

Talvez, se torne mais claro para compreender, se evocarmos uma distinção que temos que fazer quando se trata de avaliar os riscos à saúde em uma empresa: a distinção entre riscos profissionais e riscos do trabalho. No polo da desaderência, os primeiros surgem a partir das condições objetivas do ambiente (produtos perigosos, poeira prejudicial, etc.), que os expõem a riscos antecipáveis. Os riscos do trabalho, eles, se referem à dimensão enigmática da atividade humana, ao uso de si, que reconfigura, parcialmente, as condições previamente objetivadas no engajamento industrioso: nas renormalizações sob a influência de um horizonte fluído de valores que se combinam na aderência. Quando os técnicos de rádio de um hospital brasileiro escolhem deixar aberta a porta com chumbo que os protegem das radiações ionizantes para melhor cooperar entre eles e conservar um contato que acalme uma fila de pacientes ansiosos e irritados, eles renormalizam as normas de segurança, eles correm um risco que chamamos aqui "risco do trabalho". Mas é uma escolha coletiva, que reenvia a essa segunda fonte de valorização, sedimentada nos corpos-si dos protagonistas, comandando suas renormalizações, em um halo de valores, de uma outra concepção de saúde, ligada a um desejo de melhor viver

\begin{tabular}{|l|l|l|l|l|l|l|}
\hline Serv. Soc. \& Saúde & Campinas, SP & v. 18 & $1-22$ & e019013 & 2019 & e-ISSN 2446-5992
\end{tabular}




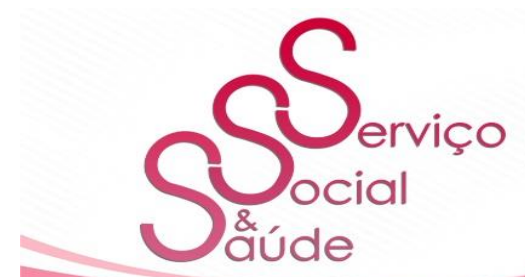

ISSN 2446-5992

(c) (i)

doi: $10.20396 /$ sss.v18i0.8658677

junto sua vida profissional (SCHWARTZ, 2015).

Vemos imediatamente como um vai e vem sinérgico deve — ou deveria - amarrar essas duas formas de riscos para uma melhor avaliação dos riscos para a saúde: fazer remontar essas renormalizações para triá-las e permitir aos produtores de normas [re]trabalhá-las no polo da desaderência.

\section{Breve retorno ao campo educativo}

Retornemos brevemente ao campo da educação, que vocês analisam muito melhor do que eu, para verificar a possível pertinência dessa postura antropológica.

No polo da desaderência, a postura normativa tem toda a legitimidade: ninguém tem o poder para reinventar a espécie humana enquanto um viver coletivo; nenhuma população humana pode viver sem produzir normas que organizam o mínimo da vida social. O agir formativo

[...] repousa sobre a busca de uma aliança entre humanos... Sem uma aliança entre os humanos, não há humanidade e essa confiança se constrói, se organiza... Assim, o educador é alguém que se coloca a serviço não do educado como um indivíduo, mas do educado como parte da humanidade (VIAL, 2010, p. 15-16) ${ }^{6}$.

Em um meio humano saturado de conceitos encapsulados em instituições, as técnicas, os ritmos sociais, essa "aliança" exige que sejam apreendidos, segundo as formas infinitamente variáveis, os diversos saberes armazenados em desaderência. A avaliação, o controle, a certificação estão de mãos dadas com o exercício futuro das responsabilidades sociais.

Mas, como disse de maneira tão apropriada o falecido Michel Vial (2010), permanecer no polo que chamamos de desaderência, é negar a necessária sinergia:

Quando o educador quer ser externo, neutro, então, é porque ele assume a postura do piloto, do guia, do Conselho [...]. O educador assume o comando

${ }^{6}$ Cf. o belo livro Vial (2010) Le travail des limites dans la relation éducative: Aide ? Guidage ?
Accompagnement ?( O trabalho os limites na relação educacional: ajuda? Guia? Acompanhamento?)

\begin{tabular}{|l|l|l|l|l|l|l|}
\hline Serv. Soc. \& Saúde & Campinas, SP & v. 18 & $1-22$ & e019013 & 2019 & e-ISSN 2446-5992
\end{tabular}




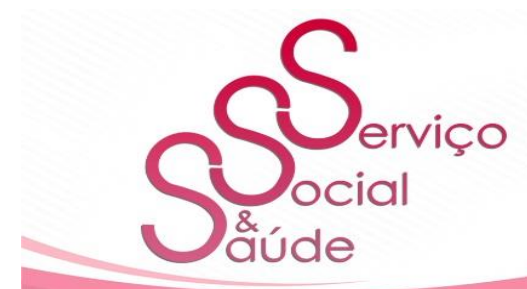

ISSN 2446-5992

(c) (i) (-)

doi: $10.20396 /$ sss.v18i0.8658677

do outro, o orienta, o instrui. Então, ele corre o risco de estabelecer uma relação ortopédica para que o outro se desenvolva canonicamente e o configure para que caminhe direito (que ele dê certo) (VIAL, op. cit., p. 15).

Para resumir: a aprendizagem é uma atividade humana, e como todas as atividades, ela se realiza numa série de debates de normas que nenhuma relação "ortopédica" poderá nivelar. Esses debates nos atravessam corpo e alma, um corpo-si construído pelo patrimônio de nossas dramáticas de uso de si anteriores. Aqui no IFFP Lausanne (junho, 2016), tivemos a honra de apresentar uma intervenção sobre "O enigma do corpo no trabalho" (SCHWARTZ, 2018) ${ }^{7}$ : essa entidade enigmática que é tomadora de decisão em todas as renormalizações, micro escolhas da atividade industriosa. É em função de múltiplos parâmetros perceptuais, sensitivos, que reativam fragmentos de memória armazenados em nosso sistema neuronal e hierarquizados por nossas relações axiológicas do mundo no qual nossos gestos profissionais são selecionados. Tomar uma boa decisão num bom momento, essa "arte do kairós", é o nosso corpo-si que é o cadinho, o operador dessa avaliação imanente. Ora, essa arte não está em jogo, para se ter sucesso, nessa delicada metabolização entre os novos saberes a serem ensinados e o patrimônio de saberes sedimentados no corpo-si do aluno? Não existe uma verdadeira arte do kairós cultivada - sem a teorizar - pela maioria dos professores para entender, tanto em relação a uma classe, quanto em relação a um aluno em particular, o bom momento, para que se opere essa metabolização? Essa tese tem sido frequentemente desenvolvida por nossa colega Nicole Caparros-Mencacci (2010), ver em Vial (2010, p. 31-57).

Isso nos permite avançar no delicado problema das sinergias, muito além do campo educacional: são dois nós de diferentes saberes e valores que nos atravessam como seres da atividade. Seja no caso dos técnicos do hospital brasileiro, ou no coração da arte de kairós, as sequências de reavaliações imanentes a todas as atividades humanas, são, para renormalizar, equipadas pelas formas de saberes, mais ou menos em penumbra, gerados nas aderências do

\footnotetext{
${ }^{7}$ Assista ao vídeo http://corsionline.iuffp-svizzera1.ch/fr/video/79 ou ler a versão escrita no número 19 da Revista Ergologia (Revue Ergologie).
} 


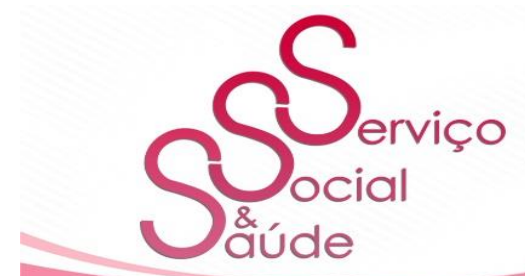

ISSN 2446-5992

(c) (i) (-)

doi: $10.20396 /$ sss.v18i0.8658677

agir. Instante após instante, a vida em nós deve reavaliar em quais condições ela pode viver, e essas reavaliações se apoiam sobre saberes ignorados, por princípio, no polo da desaderência. Há, portanto, em todas as circunstâncias, uma oposição inevitável entre um "valor dos saberes", patrimônio, provisoriamente, armazenado em desaderência, desconectado de toda avaliação do agir subjetivo; e dos "saberes-valores" que se constroem em círculos concêntricos em torno do agir em aderência. Essa dicotomia de vínculos entre saberes e valores coloca problemas críticos, epistemológicos, éticos, políticos e sociais: como construir esse terceiro polo, esse polo onde o valor dos saberes e saberes-valores podem se instruir mutuamente em uma sinergia que não seja adulterada, subdimensionada na urgência e no conflito, mas controlada (VIAl, 2010, p. 22-23)? Como coloca, notavelmente, Louis Durrive (2006)

[...] Na escola, é como se os conceitos estivessen separados da vida, mas eles não cessam de dialogar, é a própria atividade mesmo. Se os alunos conseguem aceder aos saberes, apropriá-los é porque os reinserem em sua singularidade; é claro, graças aos pedagogos, mas apesar do fato de que a Instrução pública não convoca oficialmente as vidas singulares, carregadas de debates de valor (p. III).

Na primeira parte de sua tese, Durrive tenta desvendar o enigma do aprendizado da leitura com os harkis ${ }^{8}$ autodidatas: qual "chave" (2006, p. 21)? O que na vida deles poderia dar sentido, dar valor à coisa escrita, valorizá-la, a viver na aderência uma relação pessoal com a norma armazenada no polo da desaderência (p. 27-29)?

Visando a aprendizagem escolar nesse polo da aderência, o que o apelo à comunicação chama de "desenvolvimento formativo", belos estudos foram feitos dos quais mencionaremos apenas: a "visão emancipatória da formação" (Gaston Pineau e Jean-Louis Le Grand, 2019), a dimensão "clínica" da avaliação, que conduziu Ardoino e Berger (1986) a distinguir a avaliação controle, que verifica a conformidade dos objetivos estabelecidos na desaderência, e a avaliação que se refere a critérios construídos, processualmente, no decorrer da ação.

\footnotetext{
${ }^{8}$ Grupos de populações locais que ajudaram o Exército francês durante a Guerra na Argélia, entre 1955-1962 e que foram transferidas para a França no final dessa guerra.
}

\begin{tabular}{|l|l|l|l|l|l|l|}
\hline Serv. Soc. \& Saúde & Campinas, SP & v. 18 & $1-22$ & e019013 & 2019 & e-ISSN 2446-5992
\end{tabular}




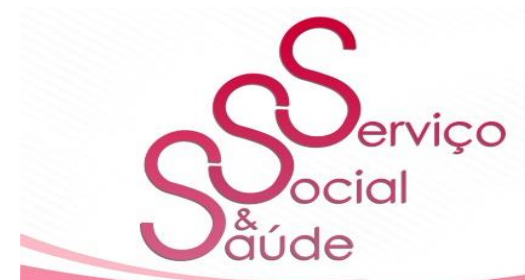

ISSN 2446-5992

(c) 10 (2)(2)

doi: $10.20396 /$ sss.v18i0.8658677

De onde nesse polo, a avaliação como uma interpretação do valor do que é feito e, no final das contas, em face de um percurso certificador de uma expertise (perícia) de Validação da Aquisição de Experiência (VAE), a preferência por "uma hermenêutica (sublinhada por nós) das situações onde pode emergir a singularidade de uma pessoa, ao mesmo tempo, competente e encarnada" (RYWALSKI, no prelo).

\section{As sinergias em penumbra}

Michel Vial, ainda, fala de um "contínuo" na relação educativa, entre "uma atitude abrangente de orientação na direção da aquisição de saberes", "prioridade dada à instrução" e "uma atitude dita 'clínica’", onde, se encontram, na maturação, "subjetividades e suas histórias" (2010, p. 285). Enquanto humana, a atividade se move em um mundo tornado social pelas normas antecedentes que devem tendencialmente fazer referência. A mera atenção à clínica das reavaliações próprias de cada aluno não pode construir o social. Mas, porque nós somos seres de atividade, nosso agir reavalia, sem cessar, o valor dessas normas antecedentes ao olhar de nosso esforço para viver em saúde, "nosso" referindo-se, conforme o caso, aos indivíduos ou às entidades coletivas variavelmente cristalizadas na história.

Contínuo? Certo, mas essa dialética "sinérgica" entre os dois polos, como nós o dissemos, é certamente uma necessidade, mas, na maioria das vezes, não controlada, subdimensionada, ficando na penumbra.

Só se pode aqui mencionar tais sinergias em penumbra. Por exemplo, no campo da Sociologia do Trabalho, François Vatin (2009), em Avaliar e valorizar recusa a ideia de que a economia seja proprietária do valor. Há uma normatividade espalhada entre todas as partes envolvidas, portanto, há critérios implícitos ligados a uns valores mais ou menos ocultos. "O poder normativo na atividade não é a prerrogativa exclusiva dos organizadores e gestionários" 9

\footnotetext{
${ }^{9}$ Nós sempre temos dito que a gestão não é o único fato dos gestores oficiais, não se trabalha "em um deserto de gestão"; já em 1988, tínhamos intitulado uma contribuição "Trabalhar, gerir"; essa é retomada em Schwartz (1992, p. 39-42).
}

\begin{tabular}{|l|l|l|l|l|l|l|}
\hline Serv. Soc. \& Saúde & Campinas, SP & v. 18 & $1-22$ & e019013 & 2019 & e-ISSN 2446-5992
\end{tabular}




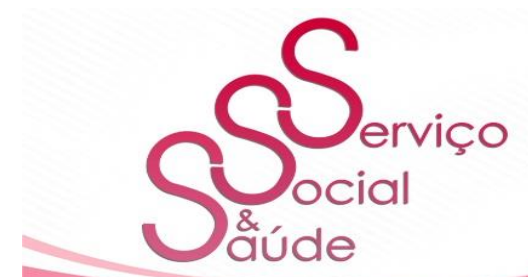

ISSN 2446-5992

(c) (1) (-)

doi: 10.20396/sss.v18i0.8658677

15

(p. 25); ele atravessa todos os profissionais, inclusive os executores, a "normatividade nativa (indigène)" contribui para a eficácia das condições econômicas (p. 30). Pode-se igualmente pensar na preocupação de quantificar as qualidades no campo econômico: devemos ver, perguntam Alexandra Bidet e Florence Jany Catrice, - apresentando um número da Revista de Socio-Economia (2017) - "o sinal de uma expectativa cada vez mais forte e significativa de controle" (p. 19-26), ou, ao contrário, tornar mais visível as avaliações diversas que atravessam obscurecidas pelas cifras, todo o campo econômico, e tirar as sinergias da penumbra?

No que concerne, mais particularmente, ao campo educativo: a sinergia tem a chance de operar corretamente entre os dois polos se puder interagir as duas formas da relação do saber em jogo. Nada poderia ser menos evidente: no polo da desaderência, o enunciado como o nível de conhecimento requerido, ou referenciais de atividade, são perfeitamente explícitos; pelo contrário, os saberes-valores que nutrem as renormalizações, que são reavaliações processuais, esses saberes-valores estão ligados às densas penumbras do agir enraizado nas histórias singulares. Há muito a extrair, é claro, da perspectiva de Vygotski (1997) entre o desenvolvimento de conceitos cotidianos e de conceitos científicos: "delimitação [...] empiricamente justificada" (p. 281). Mas é com base nos primeiros que pode aparecer o "verdadeiro" conceito (p. 270), e aqui, não há antagonismo entre os dois. Mas para nós, todo o problema social é tirar essa "interação" (p. 290) da penumbra.

$\mathrm{Na}$ apresentação de nossa tese ${ }^{10}$ (SCHWARTZ, 2012), Georges Canguilhem, a propósito da relação específica no trabalho entre os saberes e as experiências, disse: "trata-se de apreender os conceitos latentes e em torpor que fazem dos atos do trabalhador uma experiência capaz de se dizer a si mesmo, à sua maneira, pertinente, mas suscetível de elucidação crítica" (p. 20). Um projeto de elucidação essencial para uma sinergia de saberes na Universidade, capaz de transformar todos os nossos olhares sobre a avaliação: poderemos dizer que sua realização nunca foi para nós uma questão pequena.

${ }^{10}$ Texto de 1988, reimpresso a primeira edição e expandido em 2012.

\begin{tabular}{|l|l|l|l|l|l|l|}
\hline Serv. Soc. \& Saúde & Campinas, SP & v. 18 & $1-22$ & e019013 & 2019 & e-ISSN 2446-5992
\end{tabular}




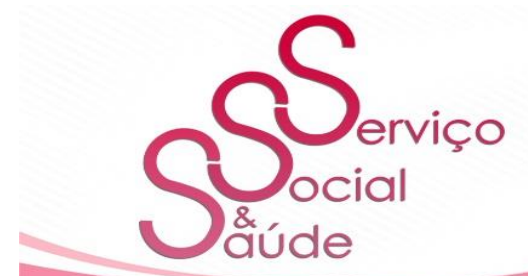

ISSN 2446-5992

(c) 10 (2)(2)

doi: 10.20396/sss.v18i0.8658677

16

Para concluir sobre esse ponto; em consonância com Vygotski, que acabamos de evocar, Bernard Prot (2007) faz uma oportuna contribuição com vistas à nossa noção de sinergia, a propósito do uso de referenciais no âmbito da Validação de Aquisições Profissionais (VAP). Pensamos nessa discordância de recursos "criativos" entre os conhecimentos desenvolvidos no trabalho, (no polo da aderência, os conceitos cotidianos) e os conhecimentos de referenciais (do polo da desaderência, conceitos abstratos): discordância que tem a vocação, na consciência do candidato, de causar uma "migração" para o "novo conteúdo da atividade", momento decisivo de uma "re-ativação do desenvolvimento do pensamento verbal e da ação prática". Estamos no coração de uma sinergia "possível". Mas se essa atividade reativa "a atividade de avaliação, pelo próprio sujeito" (PROT, 2007, p. 115), também deve ser para o júri uma reativação de sua postura de avaliador. A sinergia supõe os dois sentidos.

\section{Alguns obstáculos que tornam as sinergias tão problemáticas}

Por que essa sinergia é tão problemática? Três pontos, para o registro.

- A temporalidade das avaliações. A temporalidade das aprendizagens e das apropriações de saberes não é a dos momentos de controle (ver o no 217 da Revista Éducation Permanente dedicada aos "Ritmos e temporalidade na formação", "Rythmes et tempolarités en formation"). Os interesses da vida dão valor aos saberes em circunstâncias que não são as da desaderência. Veja o caso da leitura de autodidatas mencionada anteriormente por Louis Durrive.

Podemos avaliar apenas os indivíduos? Nossas renormalizações, nossos saberes-valores, são sempre, variavelmente socializados. Sobre essa dimensão e, num primeiro momento, a avaliação individualizada é cega. Esse é o problema, por exemplo, das "entrevistas de avaliação".

- Não há nenhuma avaliação que não se refira, em penumbra ou às claras, aos "valores", aos mundos possivelmente valorizados. E daí, a maior dificuldade: quem tem legitimidade 


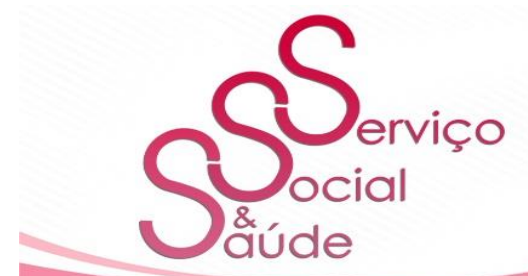

ISSN 2446-5992

(c) (i) (-)

doi: $10.20396 /$ sss.v18i0.8658677

para definir e priorizar esses mundos? Qual é a extensão temporal e espacial desse mundo comum que visam nossas valorizações? Por exemplo, hoje, qual apresentação, qual definição podemos propor do "valor democracia"? Enquanto pessoas presas por avaliações, para agir e viver, somos todos iguais. Todas as valorizações não são iguais, mas nenhuma pode se autolegitimar. Não há ciência de valores. Em uma empresa, uma pessoa que denuncia publicamente as manobras fraudulentas de sua empresa, deve ser avaliada positivamente ou negativamente para julgar suas competências, e por quem? As Matemáticas são elas um bom marcador de inteligência dos estudantes, quem pode julgar ${ }^{11}$ ? Como bem explica Ingrid Dromard (2018), seguindo uma missão para avaliar o trabalho social no Centro de Apoio à Família' ${ }^{12}$ (CAF) de Bouches-du-Rhône:

Então, o que deve ser avaliado? A efetividade da ação social do ponto de vista daqueles que a organizam e a gerem, do ponto de vista daqueles que se beneficiam ou do ponto de vista dos trabalhadores que atuam nesse campo? (p. 77)

Isso toca o ponto nodal de nosso estatuto de seres da atividade: viver supõe, para cada um, segundo a fórmula de Georges Canguilhem, recentrar, "polarizar em valor" em torno de suas normas singulares de saúde em um meio social, saturado de normas antecedentes, valorizadas em desaderência, ignorando, assim, essas polarizações. Essas polarizações atualizam, assim, as valorizações dessas normas antecedentes sempre, mais ou menos polêmicas, segundo os grupos e indivíduos humanos frente a essas normas antecedentes. Daí a inevitável dificuldade de sinergias, de dialéticas entre os dois polos.

\section{Para concluir}

As sinergias não são inventadas, elas começam com a espécie humana. A atividade humana produz normas antecedentes para viver em sociedade, mas a vida continua fazendo

\footnotetext{
${ }^{11} \mathrm{O}$ título de uma das contribuições do Atelier do Eixo 1 desse Colóquio foi: "Descreva sua concepção de inteligência e eu vou te dizer qual(is) prática(s) avaliativa(s) você tende a advogar".

${ }^{12}$ Caisse d'Allocations Familiales (CAF).
}

\begin{tabular}{|l|l|l|l|l|l|l|}
\hline Serv. Soc. \& Saúde & Campinas, SP & v. 18 & $1-22$ & e019013 & 2019 & e-ISSN 2446-5992
\end{tabular}




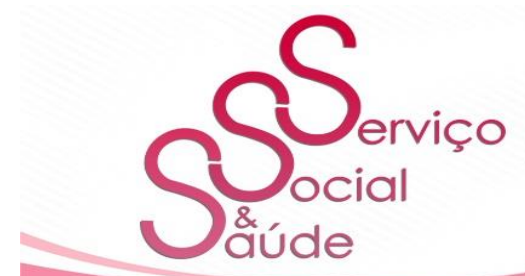

ISSN 2446-5992

(c) (1) (-)

doi: 10.20396/sss.v18i0.8658677

história, "sempre a alguma distância" dessas normas, que ela remodela com ou sem o conhecimento destas.

Essas normas antecedentes não escapam, portanto, à história: mais ou menos universais, ou pelo contrário, mais ou menos ligadas às relações de poder, de assimetria social. Nesse polo de desaderência reinam, certamente, os conceitos científicos, mas com eles estão também vizinhas regras, leis, normas que podem ser socialmente muito mais ambíguas. Para assegurar sua autoridade, no entanto, compreende-se que essas regras, normas podem usurpar o estatuto provisoriamente indiscutível desses conceitos científicos. E a partir daí, por boa ou por má-fé, eles tenderão a ignorar ou a ocultar o fazer história dos indivíduos ou grupos que avaliam, na aderência, sua relação com essas normas. O princípio do bloqueio das sinergias na vida social ${ }^{13}$ está aqui.

Então, um princípio maior: sim, deve-se certificar, controlar, fazer exames; se queremos, por exemplo, civilizar a relação de emprego, necessitamos de normas jurídicas relativas ao contrato de trabalho, à segurança. Mas, sob a condição de que esteja sempre em desconforto, insisto: as renormalizações sempre indicaram lugares onde, os princípios dessas normas, em parte, falham, - e isso é inevitável - (ver acima a questão da avaliação dos riscos profissionais).

É preciso esforçar-se para tirar a sinergia da penumbra, usinar os processos, momentos onde o valor dos saberes em desaderência possam se instruir a partir dos saberes-valores imanentes a todo agir. E, reciprocamente, embora esse recíproco pareça óbvio demais. Em suma, com toda responsabilidade, temos que pensar o retrabalho das normas antecedentes a partir das reservas de alternativas viáveis presentes nas atividades humanas. Assim, no campo jurídico, a jurisprudência, o retrabalho das noções de parentesco, de filiação; no campo das

\footnotetext{
${ }^{13}$ Em particular, bloqueando parcialmente o que chamamos de dupla antecipação no campo da formação, ver Schwartz (2013).
} 


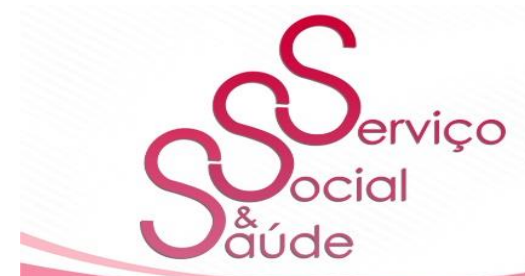

atividades econômicas, propomos a "ergogestão": sem nada tirar das responsabilidades de gestão, reavaliar as normas da organização produtiva (bens e serviços), colocando sob a luz as valorizações dos agentes que tornam todo agir industrioso possível e eficaz.

Nós experimentamos um dispositivo, os Grupos de Encontro do Trabalho (GRT, da sigla em francês de Groupe de Rencontre du Travail), que busca colocar em visibilidade essas "experiências de normas" (DURRIVE, 2015) no trabalho para tirá-las da penumbra, avaliá-las coletivamente, a fim de "desbloquear" as sinergias em sofrimento. Buscando [re]usinar parcialmente as normas antecedentes, sob o pressuposto enigmático e problemático de um terceiro polo visado, aquele de um "mundo comum a construir".

É claro que os momentos, as circunstâncias, os parceiros dessas [re]usinagens dialéticas entre os dois polos tem que ser adaptadas às práticas diferenciadas da vida social. Repensar as normas do controle dos conhecimentos na escola com a diversificação de públicos escolares requer outras disposições, diferentes da criação de um GRT na empresa. Mas entre os dois polos da aderência e da desaderência, para o tratamento da norma em nossas sociedades humanas, há ainda muito a ser feito para construir politicamente, socialmente, educativamente um terceiro polo, um polo "a-tópico", apto a tratar em tempo real a sinergia entre os dois primeiros. 


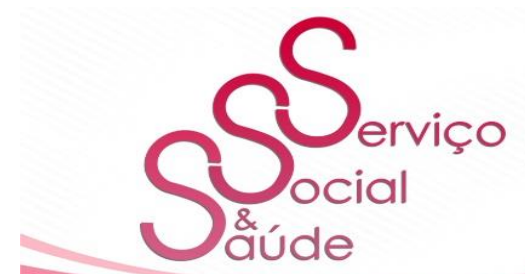

ISSN 2446-5992

(c) (1) (-)

doi: $10.20396 /$ sss.v18i0.8658677

\section{REFERÊNCIAS}

ACPPU. Association Canadienne des Professeurs d'Université. La fin des questionnaires d'évaluation par les étudiants? 2018.

ARDOINO, J.; BERGER, G. L. L’évaluation comme interprétation. Revue Pour, ${ }^{\circ}$ 107, 1986. (107), 120-127

BIDET, A.; JANY-CATRICE, F. Introduction au dossier. Quantifier les qualités. Revue Française de socio-économie. Volume 2, n 19, 2017, p.19-26.

CANGUILHEM, G. Présentation. In: SCHWARTZ, Y. Expérience et connaissance du travail. Paris : Les éditions sociales, 2017, p. 19-22.

CAPARROS-MENCACCI, N. Le cas de Camille : la limite qui donne corps. In: VIAL, M.

(Dir.). Le travail des limites dans la relation éducative: Aide ? Guidage ?

Accompagnement? Analyses de pratiques . Paris : L'Harmattan. 2010, p. 31-57.

CORTESSIS, S.; SALINI, D.; RYWALSKI, P. (Dir.). Se former au conseil et à l'accompagnement en RVAE. Entre incertitudes et projets. Éducation Permanente. mars, fora de série. IFFP, 2013.

DE KETELE, J. M. (2010). Ne pas se tromper d'évaluation. Revue française de linguistique appliquée. 2010. XV(1), 25-37. Disponível em https://www.cairn.info/revue-francaise-delinguistique-appliquee-2010-1-page-25.htm

DROMARD, I. (2018). Les groupes de Rencontre du Travail pour une évaluation ergologique du travail social. In: MALHAOUI, S.; CADET, J-P. (Dir.). La démarche ergologique, une contribution originale à la compréhension des relations entre la formation et l'emploi.

Séminaire d'Analyse du Travail (SEMAT) du Céreq, vol. 7, p. 76-91. Marseille : Centre d'Etudes et de Recherches sur les Qualification.

DURRIVE, L. L'expérience des normes: formation, éducation et activité humaine (Thèse de doctorat, Université Louis Pasteur, Strasbourg). 2006. Disponível em https://www.theses.fr/2006STR1PS01 


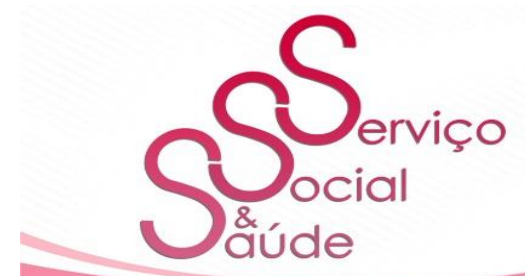

ISSN 2446-5992

(c) (1) (-)

doi: $10.20396 /$ sss.v18i0.8658677

21

DURRIVE, L. L'expérience des normes: comprendre l'activité humaine avec la démarche ergologique (Préface de F. Daniellou). 2015. Toulouse: Octarès Éditions.

GODELIER, M. L’idéel et le matériel. Pensée, économies, sociétés. Paris: Fayard. 1984. L'EVALUATION, la nouvelle mode des députés LRM. (2018, 12 juillet). Repéré à https://www.lemonde.fr/politique/article/2018/07/12/l-evaluation-la-nouvelle-mode-desdeputes-lrm_5330283_823448.html

PINEAU, G; LE GRAND, J. L. Les histoires de vie (6 éd. rev. et augm.). Paris : Presses Universitaires de France. 2019.

PROT, B. Pour sortir des idées fixes sur l'évaluation. La Revue de l'Ires, 55(3), p. 101-122. 2019. doi:10.3917/rdli.055.0101.

RYTHMES et temporalités en formation. (2018). Éducation permanente, 4(217). 2018.

RYWALSKI, P. (sous presse). Formation des adultes et démarche ergologique. Ergologia.

RYWALSKI, P. Les tâches de l'expert dans la VAE. Éducation Permanente, 2(159), 91102.2004 .

RYWALSKI, P. La validation des acquis d'expérience comme processus de formation.

Tempus Actas de Saúde Coletiva. 6(2), 85-100. 2012. Disponível em

http://www.tempusactas.unb.br/index.php/tempus/article/view/1116/0

SCHWARTZ, Y. Travail et philosophie. Convocations mutuelles. Toulouse: Octarès Éditions. 1992.

SCHWARTZ, Y. Expérience et connaissance du travail. Présentation de G. Canguilhem, 1988, Réimp. Paris: Les Éditions Sociales. 2012.

SCHWARTZ, Y. Conceptions de la formation professionnelle et double anticipation.

Éducation Permanente. 4(197), 11-27. 2013.

SCHWARTZ, Y. L'énigme du travail: risques professionnels et risques du travail. In: THEBAUD-MONY, A.; DAVEZIES, P.; VOGEL, L.; VOLKOFF, S. (Dir.). Les risques du travail: pour ne pas perdre sa vie à la gagner. Paris: La Découverte. 2015, p. 373-380. SCHWARTZ, Y. (2018). L'énigme du corps au travail. Ergologia. n 19, p. 151-174.

\begin{tabular}{|l|l|l|l|l|l|l|}
\hline Serv. Soc. \& Saúde & Campinas, SP & v. 18 & $1-22$ & e019013 & 2019 & e-ISSN 2446-5992
\end{tabular}


SCHWARTZ, Y.; DURRIVE, L. (Dir.). L’activité en dialogues suivi de, Manifeste pour un ergo-engagement. Toulouse: Octarès Éditions. 2009.

VATIN, F. Évaluer et valoriser une sociologie économiques de la mesure (Rev. et augm.). Toulouse: Presses Universitaires du Mirail. 2013.

VIAL, M. (Dir.). Le travail des limites dans la relation éducative: Aide? Guidage ? Accompagnement? Analyses de pratiques. Paris : L'Harmattan. 2010.

VYGOTSKI, L. Pensée et langage. $3^{\mathrm{e}}$ éd. Paris: La Dispute. 1997. 